\title{
EM BUSCA DO (NÃO)LUGAR DA COMUNICAÇÃO NAS ORGANIZAÇÕES
}

In search of the (no) place of communication in organizations

En busca del (no)lugar de la comunicación el las organizaciones

Profa. Dra. Lidiane Ramirez de Amorim 1 Assessora de Comunicação e Marketing da PUCRS Lidiane.amorim@pucrs.br

\section{Resumo}

Inúmeras pesquisas têm demonstrado o quanto a compreensão da comunicação organizacional como processo complexo e sistêmico tem superado a visão instrumental e linear que preponderou até meados dos anos 80. Contudo, até que ponto esse olhar contemporâneo encontra lugar no dia a dia das organizações? A partir das dimensões de lugar/nãolugar/entre-lugar (AUGÉ, 2012; BAHBBA, 1998; CASTROGIOVANNI, 2007) buscamos, com o presente artigo, identificar as possibilidades de (não)lugarização da comunicação no universo organizacional.

Palavras-chave: Comunicação Organizacional. Lugar. Não-lugar. Entre-lugar. Organizações.

\begin{abstract}
Numerous researches have demonstrated how the understanding of organizational communication as a complex and systemic process, has surpassed the instrumental and linear vision that preponderated until the mid-1980s. However, does this contemporary comprehention find its place in the day-to-day of organizations? From the dimensions of place / non-place / between-place (AUGÉ, 2012; BAHBBA, 1998; CASTROGIOVANNI, 2007), we seek, with the present article, identify the possibilities of (non) localization of communication in the organizational universe.
\end{abstract}

Key words: Organizational communication. Place. Non-place. Between-place. Organizations.

\section{Resumen}

Muchas investigaciones han demostrado cuánto la comprensión de la comunicación organizacional como proceso complejo y sistémico ha superado la visión instrumental y lineal 
que preponderó hasta mediados de los años 80 . Sin embargo, ¿hasta qué medida esta mirada contemporánea encuentra lugar en el día a día de las organizaciones? A partir de las dimensiones de lugar / no-lugar / entre-lugar (AUGÉ, 2012; BAHBBA, 1998; CASTROGIOVANNI, 2007) buscamos, con el presente artículo, identificar las posibilidades de (no) lugarización de la comunicación en el universo organizacional.

Palabras clave: Comunicación Organizacional. Lugar. No-lugar. Entre-lugar. Organizaciones.

\section{LUGARES DE FALA}

Ao imergir no universo complexo que são as organizações, inúmeros são os olhares possíveis. Da mesma forma, são múltiplos os lugares de fala quando se pretende pensar a comunicação no contexto das organizações. Compreendemos o universo organizacional como um sistema vivo, tecido por meio de relações, essencialmente composto por sujeitos, sobrecarregado de significações e simbolismos, e, com eles, se auto-eco-organiza, num constante movimento recursivo. Esse universo comunicante e produtor de sentidos (VERÓN, 2004, OLIVEIRA e PAULA, 2008) faz com que a organização "fale" além do que enuncia verbal e iconicamente. Textos que ganham vida na fala dos sujeitos organizacionais, no conjunto de discursos corporativos, e que são ressignificados também pelos sujeitos que interagem de alguma maneira com a organização.

Mas a produção de sentido no espaço organizacional vai além dos enunciados, das mensagens oficiais, da missão emoldurada e exposta na parede, portanto, da organização comunicada, aquela que se dá por meio de processos formais e falas autorizadas (BALDISSERA, 2002). Brota dos espaços, dos ambientes, das relações, dos olhares e gestos de quem compõe a organização. Ao ser também uma organização comunicante (ibidem.), ela contém processos comunicacionais que se realizam na informalidade, que vão além do que ela transmite oficialmente nas mensagens veiculadas nos canais de comunicação institucionais ou midiáticos. Também seus silêncios dizem muito sobre si, o não-dito - por vezes dito informalmente - pode ser revelador. Os sujeitos da organização e suas relações, internas e externas, estão em meio a esse emaranhado comunicativo, dando sentido a ele e sendo perpassado por ele. A organização é, portanto, um ator comunicativo, como afirma Teijeiros (2006).

Estar atento a essa polifonia que emerge no espaço organizacional é fundamental, sobretudo para os gestores e profissionais que atuam em comunicação. Para Roman (2009), 
este é um dos desafios para a própria administração da comunicação organizacional, e, seguramente, da gestão empresarial como um todo: compreender e mediar a multiplicidade de discursos que se entrecruzam no universo corporativo. Se o homem é um ser da palavra e sua ação no mundo e compreensão dele depende da linguagem e das possibilidades que encontra ou conquista para produzir e compartilhar discursos, como afirma Roman (2009), em sendo a organização um universo de significações essencialmente composto por pessoas, também sua ação no mundo e suas relações com os diversos públicos depende da sua discursividade, de tudo que ela comunica.

Neste contexto, acreditamos que dar ouvidos a estas falas e olhar atentamente não só para o que a organização transmite, mas, sobretudo, para o que ela deixa escapar enquanto organização comunicante e falada ${ }^{l}$ é um dos caminhos possíveis para descobrir que lugar/nãolugar/entre-lugar (AUGÉ, 2012; CASTROGIOVANNI, 2004, BHABHA, 1998) a comunicação organizacional ocupa no ambiente corporativo. Ir em busca do lugar da comunicação no âmbito organizacional é um convite a sair do lugar de comunicar para investigar de que maneira a comunicação é compreendida pela organização, o quanto se tem clareza sobre os seus papeis e as suas possibilidades de atuação. Assim como Pinto (2008), partimos da premissa de que é inconcebível pensar a comunicação praticada nas organizações, separadamente de uma ideia geral de comunicação. Este texto é uma possibilidade de olhar que desloca o pensamento focado unicamente nas práticas comunicativas, e dirije-se para a compreensão da comunicação no contexto organizacional, a partir dos seus níveis de lugarização. A expressão lugarização (AMORIM, 2015) advém da compreensão de lugar antropológico proposto por Augè $(2010,2012)$ e significa o processo de inclusão, legitimação e reconhecimento (ZIMMERMANN, 2010) de uma determinada dimensão, neste caso da comunicação, em um dado contexto espacial e social, neste contexto as organizações. Uma dimensão, ao estar lugarizada, significa estar plenamente inserida, incluída e, sobretudo, compreendida no contexto em que se insere.

A presente reflexão é motivada pelo transcurso das investigações na área e pela reviravolta no conhecimento acadêmico sobre comunicação organizacional, percebido a partir da década de 80 (PUTNAM, PHILLIPS E CHAPMAN, 2004; SCROFERNEKER, 2006). Em levantamento acerca da produção científica sobre comunicação organizacional, Scroferneker

\footnotetext{
${ }^{1}$ Para Baldissera (2002), a organização falada compreende os processo de comunicação informal indiretos, que se realizam fora do âmbito organizacional mas que dizem respeito à organização.

${ }^{2}$ Mais adiante definimos com mais detalhes as dimensões de lugar, não-lugar e entre-lugar.
} 
(2006) estabelece uma linha do tempo dos estudos em que é possível perceber que a visão mecanicista da comunicação esteve muito presente até este período. Uma época marcada pelo entendimento dos processos comunicacionais apenas como o ato de divulgar, transmitir, publicar. O foco era na emissão.

De lá pra cá, mais do que apenas uma atividade organizacional, ou uma área que cuida da transmissão de significados, de informação, de conhecimento e dos efeitos de diferentes mensagens, a comunicação, cada vez mais, vem sendo reconhecida como processo fundamental e intrinseco à organização, como área estratégica e aliada à gestão, até mesmo como ponto central da existência das organizações (DEETZ, 2010). É também compreendida como formativa (VAREY, 2006), pois desencadeia um processo estruturante da realidade organizacional (PUTNAM, PHILLIPS e CHAPMAN, 1999, p. 396), como constitutiva dos comportamentos organizacionais (MARQHIORI, 2009), força que promove e estimula diálogos que buscam 'lugarizar' os indivíduos na organização (SCROFERNECKER, 2010). Podemos entender também a comunicação como um processo de produção e disputa de sentidos, nas palavras de Baldissera (2004), que possibilita aos sujeitos o (re)tecer da cultura e das suas relações dialógico-recursivas e hologramáticas no contexto organizacional.

Contudo, até que ponto, de fato, essas novas formas de ver, entender e pensar a comunicação organizacional se refletem na prática, no dia a dia, na compreensão de quem vive e constroi a organização? Até que ponto a comunicação está lugarizada no contexto das organizações, nos seus espaços e entre os seus atores? Perguntas como essas foram o ponto de partida da tese de doutorado defendida em $2015^{3}$. Tais inquietações abrem caminhos e possibilidades para tecer reflexões sobre o lugar da comunicação no espaço organizacional.

\section{2 É PRECISO (RE)PENSAR A COMUNICAÇÃO}

Para perceber a comunicação como sendo capaz de perpassar todas as dimensões da organização e então buscar compreender o lugar, não-lugar ou entre-lugar que ela ocupa nas organizações, é preciso, para usar uma das expressões de Edgar Morin, uma reforma no pensamento. Um olhar que vá além da perspectiva tecnicista e cartesiana que por muitos anos predominou sob o campo comunicacional, e, de certa forma, ainda se faz presente. É por

\footnotetext{
3 O projeto de doutoramento da autora em Comunicação Social na Pontifícia Universidade Católica foi defendido em 2015, e pode ser acessada neste link: http://hdl.handle.net/10923/7256 . A tese foi vencedora do Prêmio de Teses e Dissertações da Associação Brasileira de Pesquisadores em Comunicação Organizacional e Relações Públicas (Abrapcorp).
} 
coexistirem esses dois modos de pensar a comunicação que se pode dizer que ela vive um momento híbrido.

No campo teórico-empírico, avançam estudos que dão conta de compreendê-la na sua multiplicidade e complexidade e há profissionais de mercado que compartilham dessa visão contemporânea que propõe (re)pensar o lugar da comunicação a partir de uma perspectiva complexa, processual, polissêmica, sistêmica e estratégica. Contudo, ainda é possível encontrar realidades empresariais em que, dentro de seus muros, o passado de visão funcionalista e simplista sobrevive e se materializa nos modos de fazer e pensar comunicação.

Passado e futuro convivem dialogicamente em um cenário em que a visão contemporânea da comunicação organizacional coexiste com pensamentos e práticas já superados e em meio a inúmeras incertezas. Para Cardoso (2006, p.1126) pensar a comunicação e a informação como elementos das estratégias de gestão, no contexto contemporâneo, "é um desafio que precisa ultrapassar as fórmulas superadas que estão comprometidas com a racionalidade instrumentalizada e o monopólio da verdade". A comunicação sem o compromisso estratégico, afirma o autor,

dificilmente conseguirá legitimar-se no novo cenário competitivo, correndo sério risco de se manter irrelevante e trazer pouco ou nenhum valor para a estratégia global da organização (2006, p. 1133).

Em âmbito geral, o tempo presentes exige o (re)pensar a comunicação, num contexto global, como propõe Wolton (2006). Para o sociólogo, na contemporaneidade a comunicação muda de estatuto, deixando de ser física e puramente técnica para ser

a condição de simbolização que permite o funcionamento das sociedades abertas. Está menos nas ferramentas e nos serviços onipresentes do que no papel de mediação, de "terceiro-lugar", de interface. Passa para o lado simbólico. (2006, P. 141).

Ao transgredir as ferramentas e transcender ao simbólico, a comunicação é menos informação e mais relação, diálogo, encontro de intencionalidades. Aliás, informar, definitivamente, não é comunicar, como adverte Wolton (2010) no título de sua obra mais recente. "A onipresença das tecnologias num mundo aberto, saturado de informação, não basta para diminuir as aporias da comunicação" (2010, p.12). Ou seja, a comunicação está em um nível muito mais complexo que o da mensagem, da informação, da transmissão e, por isso, Wolton contrapõe os entusiastas da utopia tecnicista contemporânea que acreditam na relação direta entre os avanços tecnológicos e a evolução da comunicação. 
No contexto das organizações, quando se pensa em comunicação, infortunadamente ainda há o predomínio de um imaginário pautado pelo que Wolton chama de deternimismo tecnológico. Como se a revolução das técnicas, as inúmeras possibilidades que elas proporcionam ao "como comunicar", por meio de novas mídias, e novas linguagens, novos canais, novos modos de dizer, acarretassem também um avanço do pensamento e da compreensão sobre comunicação organizacional.

O pensamento tecnicista da comunicação é como o pensamento insular, oposto ao pensamento complexo proposto por Morin $(2006,2005,2000)$, que inspira constantemente o tecer deste texto. Ao dar conta apenas do comunicar oficial, institucional, das mensagens e estratégias de visibilidade e imagem da organização, a comunicação organizacional encontrase enclausurada no pensamento fragmentado da super-especialização: apenas dá conta do que lhe cabe a partir do seu saber técnico. A comunicação insular é apenas parte da parte.

É preciso perceber que as organizações se realizam por e em comunicação e por isso seria ideal compreendê-la como transversal, parte do todo que carrega em si a essência da organização. Apenas estando plenamente integrada e reconhecida na/pela organização, a comunicação poderá contribuir efetivamente, não só para os objetivos estratégicos, mas sobretudo para a sua existência como ambiente integrador, como lugar de relações dialógicas, de coabitação, de desenvolvimento humano (MUMBY, 2010).

Ao partir desse olhar para pensar o lugar da comunicação nas organizações, o foco está na compreensão e não nas atribuições, está mais no pensar que no fazer, entendendo que o fazer materializa o pensar. No contexto corporativo, a área que responde pela comunicação não pode deixar de cuidar do que lhe cabe no âmbito da técnica, afinal também se trata de um saber prático que oferece uma série de soluções, canais, ferramentas, etc, e nisso, há inúmeros exemplos bem-sucedidos, de grandes avanços nas realidades empresariais e pesquisas que mostram a importância dessa atuação. O que provoca estas linhas, no entanto, e abre outras possibilidades de reflexão está no campo da compreensão, da percepção, é o olhar a conunicação pelos olhos da organização, a partir do que ela transmite e emite, para usar as expressões de Goffman (1975) que tão bem complementam esses dois lugares de fala: o que a organização transmite enquanto organização comunicada, e emite enquanto organização comunicante. 


\section{EM BUSCA DO LUGAR}

Falar em lugar, a partir da perspectiva de Augé, não significa abordar as noções de espaço físico-geográfico. O lugar antropológico, proposto pelo autor, carrega consigo a compreensão dos percursos que nele se efetuam, dos discursos que nele se pronunciam e da linguagem que o caracteriza.

Por trás da ronda das horas e dos pontos fortes da paisagem, encontramos, na verdade, palavras e linguagens: palavras especializadas da liturgia, do "antigo ritual", em contraste com aquelas da oficina "que canta e tagarela"; palavra também de todos os que, falando a mesma linguagem, reconhecem que elas pertencem ao mesmo mundo. O lugar se completa pela fala, a troca alusiva de algumas senhas, na conivência e na intimidade cúmplice dos locutores (AUGÉ, 2012, p. 73).

Logo, lugar define-se como identitário, relacional, histórico e se dá na articulação de linguagens, de atos comunicativos, na convivência na palavra ritualizada e informal, dos discursos oficiais e os que escapam a estes, em um universo de bem-ditos, mal-ditos e nãoditos (ROMAN, 2009). O lugar se constrói em meio a sensibilidades e fragmentos identitários do sujeito ou da dimensão que ali se lugariza. Uma dimensão lugarizada, significa dizer que entre ela e o lugar há um vínculo constituído, uma ligação que a torna parte, uma sensação plena de pertencimento.

Para Roman, não há enunciado neutro, portanto, os discursos organizacionais, necessariamente, inscrevem-se nas categorias citadas acima. Enquanto os bem-ditos são produzidos na esfera dos relacionamentos administrativos, os não-ditos nascem e circulam na esfera dos relacionamentos pessoais e afetivos. Tecendo relações com as dimensões de organização comunicada, comunicante e falada (BALDISSERA, 2002, 2010), podemos dizer que o conjunto de enunciados institucionais que constituem o gênero de discursos bem-ditos, estão no nível da organização comunicada. Já o cojunto de enunciados verbais nãoinstitucionais produzidos na clandestinidade na organização, os mal-ditos, integram a organização comunicante e falada, onde também circulam os enunciados mal-ditos interditados ou impedidos de serem explicitados, que constituem o gênero dos discursos nãoditos.

Retomando as dimensões de lugarização, os não-lugares, ao contrário do lugar, pressupõem a ausência de vínculos, é onde nem a identidade, nem a relação, nem a história fazem sentido. Um não-lugar é como um lugar vazio de significações, uma dimensão não- 
lugarizada não estabelece a relação de pertencimento, está por estar, por um fim bruto, é o texto pelo texto. "Assim como os lugares antropológicos criam um social orgânico, os nãolugares criam tensão solitária" (AUGÉ, 2012, p. 87). Não quer dizer que os não-lugares estejam vazios de relações, no entanto, configuram-se em não-lugares pelo sentido que essas relações possuem, que dizem respeito apenas a seus fins, como é o caso da relação dos indivíduos com o comércio, transporte e trânsito, tal como exemplifica Augé. Um lugar onde as relações são intermediadas apenas por discursos prescritivos, imperativos, informativos:

\begin{abstract}
os não-lugares da supermodernidade, aqueles que tomamos emprestados quando rodamos na auto-estrada, fazemos compras no supermercado ou esperamos num aeroporto (...) definem-se, também, pelas palavras ou textos que nos propõem: seu modo de usar, em suma, que se expreime conforme o caso, de maneira prescritiva ("pegar a fila da direita"), proibitiva ("proibido falar") ou informativa ("você está entrando em Beaujolais") e que recorre tanto a ideogramas mais ou menos explícitos e codificados quanto à língua natural (AUGÉ, 2012, p. $89)$.
\end{abstract}

Não há diálogo, afeto, trocas, não há formação de identidade e as mensagens são dirigidas a todos, indiscriminadamente. A relação mais frequente em não-lugares é a contratual, funcional: a passagem que se compra, o cartão que se deve apresentar no pedágio (AUGÉ, 2012), as regras estabelecidas e aceitas tacitamente por todos que ali se encontram.

Quando há a sensação de um lugar provisório, onde não se estabelecem raízes concretas, porém não há a ausência plena de significação, trata-se do entre-lugar, na perspectiva de Castrogiovanni (2004) e Bhabha (1998). Ele se configura em um terreno para a elaboração de estratégias de subjetivação "que dá início a novos signos de identidade" (BHABHA, 1998, p. 20), um espaço intersticial, que está entre duas partes, um tecer que já não é mais o que era no começo e ainda não se tornou o que será no fim. Bhabha fala de entre-lugares quando se refere aos locais de fronteira, como fronteiras culturais cujas identidades emergem no jogo de diferenças que se estabelece. É onde "as experiências intersubjetivas e coletivas de nação, o interesse comunitário ou o valor cultural são negociados" (1998, p. 20) e é também onde se formulam estratégias de negociação e de representação.

Scroferneker (2010) utiliza as dimensões de lugar para pensar as relações entre os sujeitos e a organização ao compreendê-la como um espaço em que lugares e não-lugares são produzidos e reproduzidos, fazendo emergir o entre-lugar. A organização, nesta perspectiva, é um universo complexo em que as relações são (re)tecidas na tentativa de "lugarizar" os 
indivíduos. Pensar a organização dessa maneira, significa ter presente as dimensões de vínculo, relações, identidade, cultura e pertencimento que circulam neste espaço.

Neste artigo, propomos as noções de lugar/não-lugar/entre-lugar para pensar a compreensão que a organização possui da comunicação, a partir dos lugares institucionais e discursivos a ela concedidos, das dimensões de organização comunicante e comunicada. $\mathrm{O}$ lugar institucional está no nível da organização comunicada, ou seja, é o que consta nos documentos, regimentos, políticas e em outros discursos oficiais da organização. Já o lugar discursivo diz respeito à compreensão de comunicação que emerge no nível da organização comunicante, ou seja, nas relações comunicacionais que os sujeitos estabelecem diretamente com/na/sobre a organização, nos processos de comunicação informal, nos diálogos, nas falas dos sujeitos organizacionais. É no entrecruzar destes dois lugares que se abre uma possibilidade para identificar se a comunicação está lugarizada, não-lugarizada ou está em um entre-lugar no âmbito organizacional.

\subsection{Quando a comunicação é/está (não)lugarizada?}

Com base nas dimensões de lugar, não-lugar e entre-lugar em relação à compreensão de comunicação, é possível tecer possibilidades acerca de sua lugarização. Em organizações em que a gestão e seus profissionais compartilham do olhar contemporâneo sobre a comunicação, sendo capaz de percebê-la como parte e processo fundamental e não a partir das lentes mecanicistas e funcionalistas, é possível que a comunicação esteja/seja lugarizada. A comunicação plenamente lugarizada no espaço organizacional é aquela que é considerada parte intrínseca da organização, que está envolvida no pensar das estratégias, nas tomadas de decisões, que é legitimada perante todos os setores e possui espaço e lugar de fala.

Nestas organizações, não há vácuo entre o seu lugar institucional, previsto no organograma, nos regimentos, nas diretrizes, e o lugar discursivo, aquele que emerge da fala dos atores e dos enunciados organizacionais. As dimensões comunicante e comunicada da organização são coerentes, com respeito à compreensão de comunicação. A coerência, aliás, é a marca desse tipo de organização que possibilita à comunicação organizacional a existência plena e a compreende da maneira ideal, ou seja, complexa, múltipla, sistêmica e estratégica, vital para a existência da organização.

Quando a relação entre a organização e a comunicação é pautada unicamente pela funcionalidade, identifica as organizações em que a comunicação encontra-se não-lugarizada. O não-lugar da comunicação na organização se dá quando a compreensão que a organização 
tem dela é aquela da visão mecanicista e cartesiana: como uma ferramenta que transmite informações, como um canal de emissão, como mera produtora de canais/materiais de comunicação, e isso fica claro ao se analisar o que ela transmite enquanto organização comunicada e emite, no nível da organização comunicante. Outra possibilidade são organizações que não possuem um setor estruturado para cuidar da comunicação e que sanam suas necessidades através de empresas terceirizadas, cuja relação é meramente contratual. Nesta perspectiva, a comunicação não está lugarizada. Não há vínculo além daquele econômico-financeiro.

Já quando há internamente um setor responsável, porém ele encontra-se desvinculado do todo da organização, também configura-se como não-lugarizada. Os profissionais de comunicação são chamados apenas ao fazer, depois de tomadas todas as decisões. "Precisamos do cartaz, do folder, da notícia no site e de flyers para distribuição". A comunicação não-lugarizada é chamada pelos gestores apenas neste estágio, está presa ao operacional, e os sujeitos organizacionais não a percebem para além disso. Logo, a comunicação não-lugarizada, é aquela não legitimada como estratégica, não há lugar para o seu pensar, apenas para o seu fazer.

No contexto híbrido vivido pela comunicação organizacional atualmente, o entre-lugar está representado pelas organizações em que o olhar contemporâneo sobre comunicação começa a tomar forma, já está presente para os seus gestores, por exemplo, ou para os profissionais da área, porém não totalmente disseminado entre todos os setores da organização. Ora a comunicação é chamada a ser estratégica, ora é apenas operacional. Encontra-se no caminho da legitimação, com alguns resultados ganhos, mas ainda com um percurso a percorrer.

\section{CAMINHOS E OLHARES POSSÍVEIS}

Lugares, não-lugares e entre-lugares não são estanques, imutáveis, determinados. " $\mathrm{Na}$ realidade concreta do mundo de hoje, os lugares e os espaços, os lugares e os não-lugares misturam-se, interpenetram-se. A possibilidade do não-lugar nunca está ausente de qualquer lugar que seja (...) Lugares e não-lugares se opoem (ou se atraem), como as palavras e as noções que permitem descrevê-las" (AUGÉ, 2012, p. 98). Como afirma Scroferneker (2009), lugares, não-lugares e entre-lugares são demarcados e remarcados em constantes movimentos e acabam por (re)significar as noções de espaço e tempo. 
Quer dizer que o jogo de legitimação, inclusão, compreensão da comunicação organizacional pode ir do não-lugar ao lugar, quando ela está a trilhar um caminho rumo à lugarização. O contrário também é possível. Quando ocorre uma troca de gestão, por exemplo, e o comando da organização é assumido por lideranças menos preparadas para lidar e compreender a comunicação, abre-se caminho para o retrocesso, pode-se ir do entre-lugar ao não-lugar, cruzar a fronteira de volta para o começo.

Do ponto de vista empírico, no âmbito da análise discursiva, há outros caminhos possíveis. A Escola de Montreal, corrente de pensamento que nasceu nos anos 90 no departamente de Comunicação da Universidade de Montreal, tem como pressuposto a ideia de que organização emerge da comunicação (CASALI, TAYLOR, 2003). Para os pensadores desta corrente, é na relação entre textos e conversações, que por sua vez extrapolam o tempo e espaço em que são produzidos, que as organizações se constroem, sendo, portanto, conceituadas como uma configuração de pessoas, tecnologias, edifícios e objetos que se mantêm unidos pela mais frágil das amarras: comunicação.

A proposta de análise desta escola se dá através da análise focada em como a realidade é construída nas conversas cotidianas dos sujeitos organizacionais na medida em que realizam suas tarefas diárias. Para entender o lugar da comunicação nas organizações também se tem como ponto de partida as falas e os discursos informais que denotam a compreensão que os individuos possuem sobre a comunicação organizacional.

Contudo, para pensar os níveis de (não)lugarização da comunicação organizacional, acreditamos que é preciso também analisar o que está posto, os enunciados corporativos oficiais, a maneira como a organização se apresenta e apresenta sua comunicação. Eis outro olhar entre tantos possíveis. A intenção deste texto não é definir a melhor lente, mas sim, deixar em aberto possibilidades de reflexões e caminhos a serem trilhados, que contribuam para o campo do pensamento e da prática da comunicação organizacional.

\section{REFERÊNCIAS}

AUGÉ, Marc. Não-lugares: Introdução a uma antropologia da supermodernidade. Campinas, São Paulo: Papirus, 2012.

Por uma antropologia da mobilidade. Maceió: Editora Unesp/UFAL, 2010.

BALDISSERA, Rudimar. A teoria da complexidade e novas perspectivas para os estudos de comunicação organizacional. In KUNSCH, Margarida M. K. Comunicação organizacional: histórico, fundamentos e processos. V. 01. São Paulo: Saraiva, 2009, p. 133-164. 
Comunicação organizacional na perspectiva da complexidade. In Organicom. Ano 06, n 10/11, 2009. Disponível em http://www.eca.usp.br/departam/crp/cursos/posgrad/gestcorp/organicom/re_vista10-11/115.pdf . Acessado em 17/01/2011.

Organizações como complexus de diálogos, subjetividade e significação. In: KUNSCH, Margarida M. K. (Org.). A comunicação como fator de humanização das organizações. São Caetano do Sul, SP: Difusão, 2010, p. 61-76;

BHABHA, Homi. O local da cultura. Minas Gerais: Editora UFMG, 1998.

CASALI, Adriana; TAYLOR, James. Comunicação Organizacional: uma introdução a perspectiva da "Escola de Montreal". Revista Estudos de Jornalismo e Relações Públicas. Universidade Metodista de São Paulo - vol.1, n.1 (jun. 2003). São Bernardo do Campo: Umesp, 2003. p. 28-40.

CASTROGiOVAnNI, Antonio. A geografia do Espaço Turístico como Construção Complexa da Comunicação. Porto Alegre: Tese (doutorado), Faculdade de Comunicação, PUCRS, 2004. Exemplar fotocopiado.

. Lugar, no-lugar y entre-lugar. Los ángulos del espacio turístico. In: Estudios y Perspectivas en Turismo. Buenos Aires: Centro de Investigaciones y Estudios Turísticos. V. 16, $\mathrm{n}^{\mathrm{o}} 1$, 2007. p. 5-25 ISSN 0327-5841.

DEETZ, Stanley. Comunicação organizacional: fundamentos e desafios. In: MARCHIORI, Marlene (Org.). Comunicação organizacional: reflexões, processos e práticas. São Caetano do Sul, SP: Difusão, 2010, p. 83-101.

GOFFMAN, Erving. A representação do eu na vida cotidiana. Petrópolis, RJ: Vozes, 1975, p. 1174.

MORIN, Edgar. O método 4. 3.ed. Porto Alegre: Sulina, 2002. p. 15-64.

O Método II: a vida da vida. 3.ed. Porto Alegre: Sulina, 2005.

Introdução ao pensamento complexo. (2006). Tradução Eliane Lisboa. Porto Alegre:

Sulina.

Educação e complexidade: os sete saberes e outros ensaios, 4 ed. São Paulo: Cortez, 2007.

MUMBY, Dennis K. Reflexões críticas sobre comunicação e humanização das organizações. In: KUNSCH, Margarida M. K. (Org.). A comunicação como fator de humanização das organizações. São Caetano do Sul, SP: Difusão, 2010, p. 19-39.

OLIVEIRA, Ivone de Lourdes; PAULA, Maria Aparecida. Comunicação no contexto das organizações: produtora ou ordenadora de sentidos? In: OLIVEIRA, Ivone de L.; SOARES, Ana Thereza N. (Orgs.). Interfaces e tendências da comunicação no contexto das organizações. São Caetano do Sul, SP: Difusão, 2008, p. 91-108.

PINTO, Julio. Comunicação organizacional ou comunicação no contexto das organizações. In: OLIVEIRA, Ivone de L.; SOARES, Ana Thereza N. (Orgs.). Interfaces e tendências da comunicação no contexto das organizações. São Caetano do Sul, SP: Difusão, 2008, p. 81-9. 
PUTNAM, L. L.; PHILLIPS, N.; CHAPMAN, P. Metaphors of communication and organization. In: CLEGG, S. R.; HARDY, C.; NORD, W. R. (Eds.). Managing organizations: current issues. London, UK: Sage, 1999. p. 375-402.

ROMAN, Artur Roberto. Organizações: um universo de discursos bem-ditos, mal-ditos e não-ditos. In: KUNSCH, Margarida M. K. (Org.). Comunicação organizacional: linguagem, gestão e perspectivas. V. 2. São Paulo: Saraiva, 2009, p. 125-57.

SCROFERNEKER, Cleusa. Comunicação e cultura organizacional: a complexidade dos diálogos '(in)visíveis'. In: MARCHIORI, Marlene (Org.) Faces da cultura e da comunicação organizacional. v. 2. São Caetano do Sul, SP: Difusão, 2010, p. 185-97.

O diálogo possível: comunicação organizacional e paradigma da complexidade. Porto Alegre: EDIPUCRS, 2008.

Trajetórias teórico-conceituais da Comunicação Organizacional. In Revista Famecos - mídia, cultura e tecnologia. Porto Alegre: dezembro 2006.

VERÓN, Eliseo. Fragmentos de um tecido. São Leopoldo: Unisinos, 2004.

WOLTON, Dominique. É preciso salvar a comunicação. Trad. Vanise Pereira Dresch. São Paulo: Paulus, 2006.

2010.

Informar não é comunicar. Trad. de Juremir Machado da Silva. Sulina: Porto Alegre:

Original recebido em: 05 de outubro de 2011

Aceito para publicação em: 18 de fevereiro de 2016

Lidiane Ramirez de Amorim

Doutora em Comunicação pela Pontifícia Universidade Católica do RS (PUCRS), com estágio doutoral na Universidad Complutense de Madrid (UCM-Espanha). É Mestre em Comunicação pela mesma universidade, com formação em Comunicação Institucional pela Universidade Austral (Arg) e graduação em Comunicação Social, habilitação Jornalismo, pela

Universidade Federal de Santa Maria (2006). Teve sua tese de doutorado reconhecida nacionalmente ao ser vencedora do Prêmio de Teses e Dissertações da Associação Brasileira de Pesquisadores em Comunicação Organizacional e Relações Públicas (Abrapcorp). Atua profissionalmente como Assessora de Comunicação e Marketing da PUCRS.

Esta obra está licenciada sob uma Licença Creative Commons. 